\title{
Are networked legislators better at their jobs?
}

\author{
Jennifer Nicoll Victor \\ Schar School of Policy and Government \\ George Mason University \\ September 2020 \\ For presentation at the annual meeting of the American Political Science Association, \\ held in virtual format, September $9-13,2020$ \\ Working paper, not for citation
}

\begin{abstract}
The United States Congress has been on a steady path of deepening partisan polarization for several decades, and many have questioned Congress's ability to perform its basic functions with integrity, such as lawmaking, budgeting, and approving presidential nominations. Some observers have questioned whether some gridlock can be overcome on Capitol Hill by deepening relationships among legislators, encouraging norms of civil behavior, and helping members to make connections with crosspartisans. In this paper I examine the extent to which voluntary legislative organizations, or House caucuses, perform that function. I conceptualize participation in voluntary legislative organizations as way for members to access a network of bipartisan legislators and examine whether those connections affect legislators' individual effectiveness as lawmakers. Using congressional data from 1993 - 2016 (103rd to 114th Congresses), I find that eigenvector centrality in the House caucus network positively predicts individual legislative effectiveness.
\end{abstract}




\section{Introduction}

This paper represents a subset of a larger project that examines the consequences of partisan polarization in the United States Congress. Specifically, the larger project examines the role that relationships play among members of Congress and their ability to work together to achieve legislative goals. Partisan polarization in the US Congress is a problem that is increasing in size and scope. Traditionally, legislating involves a fair amount of cooperation among political rivals. The lawmaking process outlined by the United States Constitution inhibits purely majoritarian policymaking. In other words, an effective Congress requires some amount of bipartisan cooperation among its members. It is therefore important to understand the various relationships within and between members of Congress and how those relationships affect legislators' ability to perform the basic functions of the institution.

A growing number of scholars are engaged in investigating the importance of connections among members of Congress. To some extent, curiosity about this topic is driven by a general conventional wisdom that humans in a decision-making group find more points of agreement with one another when they are socially connected to one another. The basic idea that people who interact in low stakes exchanges, social situations, or casual discourse develop a familiarity with one another that may create the conditions to work together even when the work maybe contentious. Some have suggested that if members of Congress have more dinner parties with one another, spend more time together outside of the office, or attended one another's children's baseball games, that Congress might be a more functional place (Uslaner 1993). But for all the studies about the importance of relationships in group decision-making, we cannot really be sure that this conventional wisdom is true. The dysfunction in Congress has grown so strong in recent years by some measures that the idea that more cocktai parties would fix Congress seems like a trite response to a systemic problem. In fact, given research about motivated reasoning and affective polarization, it will not be unreasonable to think that increased socialization could worsened polarization in Congress. The need for a deeper understanding about how relationships and connections among members of Congress affect their capacity to perform their lawmaking function is readily apparent.

This paper has two primary objectives. First, I outline a broad theory of legislative behavior that integrates insights from rational choice theory and social network theory 
that aims to provide a foundation for the study of Congress. Succinctly, for several decades political scientists have understood the importance of institutions for explaining human behavior, the political institutions of the United States Congress are broadly understood to be the primary constraint on the capacity of the legislature to do just about anything. On the other hand, in the last 10 years or so the discipline has developed a strong appreciation for the impact of relationships on political outcomes. The theory developed in this paper aims to reconcile these points of view.

Second, this paper draws one narrow observable implication from the theory and performs a direct empirical test. Specifically, I ask whether legislators who are more connected to one another via their participation in low stakes legislative organizations are more effective at their jobs. The results of a statistical analysis across a quarter century of recent congressional behavior are consistent with the implication of theory. In other words, legislators who are more highly connected to one another are more effective lawmakers.

\section{Theory}

The most fundamental lesson of political science in the last 100 years is that institutions matter. The rules of the game determine its outcome. Rational choice theory as applied to questions of politics has largely been adopted from the field of economics; however, political scientists have mad using this paradigm that help us to better understand many varieties of human behavior (Downs 1957; Riker and Ordeshook 1968; Riker 1980; Riker, William 1988; Shepsle 1979; 2010). The basic idea that the institutions, or rules, of any system structures the behavior of a system's participants, and the outcomes they are able to produce, has been applied to every subfield from the study of war to individual voter behavior. This individualistic, pragmatic point of view for studying human behavior has led to many great insights over the last number of decades, but the limitations of the paradigm have become increasingly apparent.

A more sociological view of human political behavior has been prominent in various subfields of political science since the 1950s, that was sometimes overshadowed by its more rigorous sibling, rational choice theory (Berelson 1954; Lazarsfeld, Berelson, and Gaudet 1948; Huckfeldt and Sprague 1987; 1988; Sokhey and Djupe 2011; Mutz 2002; McClurg 2006). However, the relational view may have been ahead of its time. While 
the behavioral revolution in political science soared in the mid-twentieth century, the computational tools and advanced mathematics that would be needed to test fully the implications of those theories would not be available until the end of the century.

Contemporary scholars of politics are therefore left to question the extent to which institutions and relationships among institutional actors differentially affect human behaviors. We know the institutions matter. We also know that institutions are made up of, and created by, individuals who have various interdependent relationships with one another. To some extent, this leaves political science with a chicken-and-egg dilemma: do institutions create the relationships that impact human behavior? Or does interaction among humans create the institutions that drive behaviors and outcomes? These processes are interdependent, like the chicken and its egg.

Understanding the interplay of institutions and relationships is important for advancing our understanding of the political behavior of individuals and the political outcomes generated by institutions of politics (legislatures, countries, agencies, organizations, constituencies, etc.). Scholarship benefits from a grand theoretical perspective for understanding the relative contributions of institutional constraint and relational constraint on political behavior.

Figure 1 Institutional Theory of Relational Political Behavior

Institutional Theory of Relational Political behavior

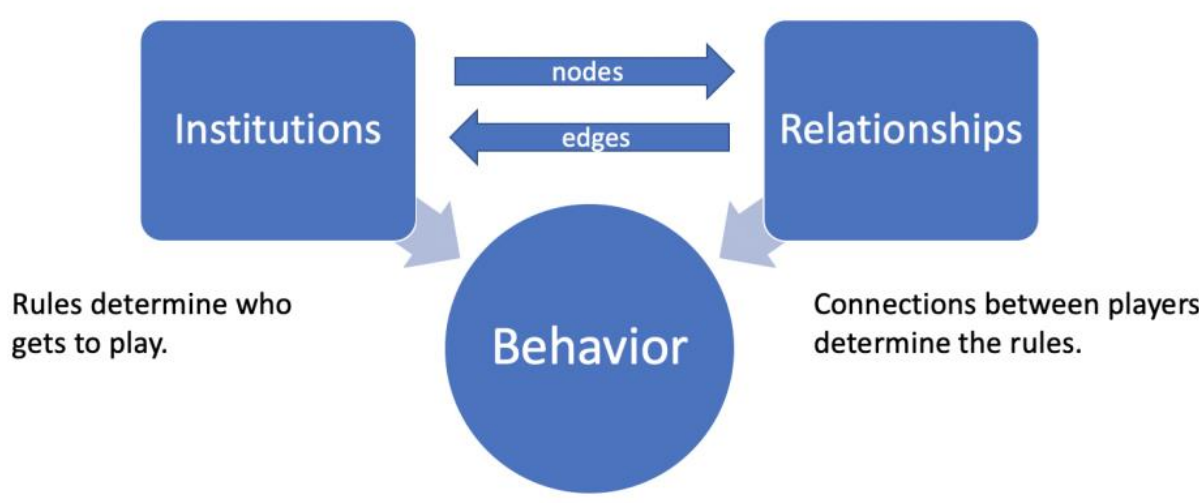

Figure 1 depicts the inter-dynamics of institutions and relationships for political behavior proposed in this project. Institutions affect political behavior by providing constraints in the form of rules that, when violated, may result in negative consequences, or when followed, may result in selective benefits. Relationships also have a direct impact on political behavior as known structures of connections between individuals affect the outcomes they generate. For example, closed triads generate 
trust and cooperation among participants, and reciprocity between dyads generates expected behaviors and tit-for-tat strategic activity (Wasserman and Faust 1994). These basic patterns of political behavior are well established in political science.

Going further, I suggest that the relationship between institutions and the connections among political actors can be understood through a social network lens. Institutions, or the rules of any political interaction, determine the nodes, or the players in the game. In democracies, election rules determine who votes. In legislatures, rules about lawmaking determine which bills advance. In political parties, nominating procedures determine which candidates sit for elections. In international treaties, the letter of the agreement outlines its signatory participants. The institutions may also affect the interactions among these players, but their primary impact is on identifying who gets included.

Once the set of players is established and some decision-making process has begun, a pattern of relationships and connections are made among the players. In elections, these patterns make up party coalitions. In legislatures, the connections among lawmakers affect the content of the proposed bills. In political parties, the connections among partisans determine the intra-group factionalism. Among the signatories of a treaty or pact, the connections of participants determine the ability to enforce agreements. These patterns have a feedback effect on any subsequent rules that are generated in the group. The rules determine who plays. The connections determine the rules. Together these two forces make-up the institutions and connections that generate individual behaviors and group outcomes.

In this most basic way, if we think of political behavior as the outcomes produced by a network of connected political actors, the institutions determine the nodes of the network, and the relationships among the nodes determine the edges of the network. The connections may subsequently influence further institutions or rules, changing the make-up of players, and as the players change as a result of rules changes, the pattern of relationships are affected. Together, the nodes, edges, and emergent properties of the network produce the various individual and group behaviors that generate outcomes. But understanding those outcomes requires that we understand the players and the ways in which they are connected.

To draw a metaphor, suppose we think of a political process like a soccer match. The rules of the match structure the game, but these rules alone do not produce the outcome. We cannot predict the winner of the game by reading the rulebook. The rules of the match may determine which teams play, and the rules of the teams may determine which players are on the team or on the field, but even with this information we cannot understand outcomes absent some information about the interactions that 
occur between the players. The playing of the match generates a constant and dynamic set of interactions among the players. As the interactions go-on, coaches may select different players to include the in match as a way to advantage their team. The constant interdependence of the rules and the interactions, together, produce the outcome of the game. While oversimplified, the metaphor and model demonstrate the necessity of understanding institutions and relationships to explain political outcomes.

A feature of this model is that the institutions are more stable than the relationships, therefore the nodes are more stable than the edges. This basic implication of the model fits with politics and a basic understanding of dynamic, complex systems. It also fits with politics, where political actors tend to be more constant than the relationships among them.

Additionally, where nodes have more connections and participate in more subgraphs of a network, they have more opportunities to participate in determining the outcomes of the game. In a legislative setting, this would look like a legislator who has more connections to other legislators, rendering that legislator with more possible ways to advance goals, bills, or otherwise impact the legislative process, which could also be stalling bills.

The single observable implication that I draw from this model and test in this paper is the following:

H: Legislators more connected to other legislators will be more effective compared to legislators who have relatively fewer connections among their peers.

\section{Research Design}

I test the above hypothesis on a dataset of 1103 members of the United States House of Representatives who served between 1993 and 2016. The analysis includes every representative who served a complete term in this time period.

Using a mixed linear statistical model, I predict the behavior of the legislators with a dataset of variables that measure factors that are known to impact behavior.

\subsection{Dependent variable}

The dependent variable is drawn from the Legislative Effectiveness Scores provided by the Center for Effective Lawmaking and developed by Alan Wiseman and Craig Volden (Volden and Wiseman 2014). Legislative Effectiveness Scores are 
aggregated from 15 factors that measure the ability of a legislator to advance legislation, including the number of sponsored bills and those that get legislative action at various stages of the legislative process including committee, post-committee, floor action, passage, and further actions. Bills are weighted for being substantive, commemorative, or significant. The measure has been used widely and is exhibits strong validity and reliability.

\subsection{Independent Variables}

I seek to test the effects of voluntary connectivity among legislators on their legislative effectiveness. In the U.S. Congress, the best example of voluntary legislative organizations are congressional member organizations, commonly called caucuses. To capture connectivity among legislators I calculate the eigenvector centrality of members in caucus networks of each congress.

Caucuses are loosely regulated voluntary organizations on Capitol Hill. Members of Congress can join as many or as few of these groups as they like, and the groups themselves vary considerably in their level of formality, organization, and regular function (Hammond 2001; Ringe and Victor 2013; Victor and Ringe 2009). Caucuses are organized on hundreds of topics ranging from industry groups, as in gas or corn, to diseases, such as Parkinson's and Alzheimer's, as well as international topics and regions, and personal interests, boating and wine, for example. Forming a caucus is relatively simple, but caucuses are not allocated resources from the House. They are not allowed staff, stationary, office space, or other resources. Members and their staff run these organizations from their personal offices, and most of them have bipartisan co-chairs.

Caucuses are casual organizations and there is wide variation among them in terms of how systematic and functional they are. Some caucuses are highly organized, with regular events, newsletters, and leadership meetings; while other caucuses may only exist as an electronic email listserv and hold infrequent meetings or events. Caucus membership tends to be fluid and records are somewhat scarce. Caucuses are supposed to register with the House Committee on Administration, and many do, but there are no consequences for operating an unregistered caucus and there are dozens, or maybe even hundreds, that fall through administrative cracks.1 The House

1 The caucus membership data used in this research has been hand collected by the author by recording individual member's caucus memberships as listed in Congressional Yellow Books (Directories 2012). Yellow Books are published quarterly, but I record data from a single directory 
Committee on Administration does not maintain membership lists for any caucus. Not all caucuses maintain websites or other public records of their memberships, so individual data collection is the only way to attempt to assemble the complete population of caucus memberships. In addition, there exists no systematic data on caucus activity. There are no records that would tell us, for example, how often a caucus meets, how engaged its members are, or how frequently its members interact with one another. While this information would be a far superior measure of connectedness through voluntary organizations, membership is a flawed but reasonable proxy.

Over the past few decades, the number of caucuses has proliferated in Congress. Importantly, most of the growth in caucuses has been in bipartisan voluntary groups. Error! Reference source not found. shows the steady growth in the number of congressional caucuses from 1993 to 2016, over the same time period as the decline of cross-party co-voting.

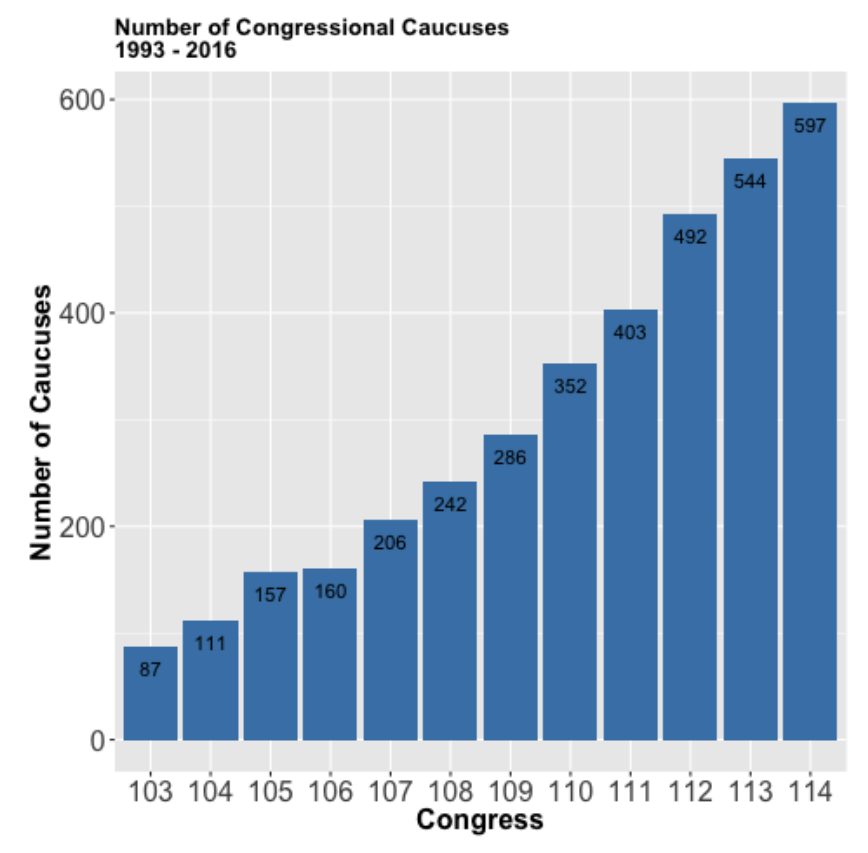

Figure 2 Number of Congressional Member Organizations (Caucuses), 1993-2016

for each Congress, introducing some measurement error. To date, there is no alternative source of caucus membership data more comprehensive. 


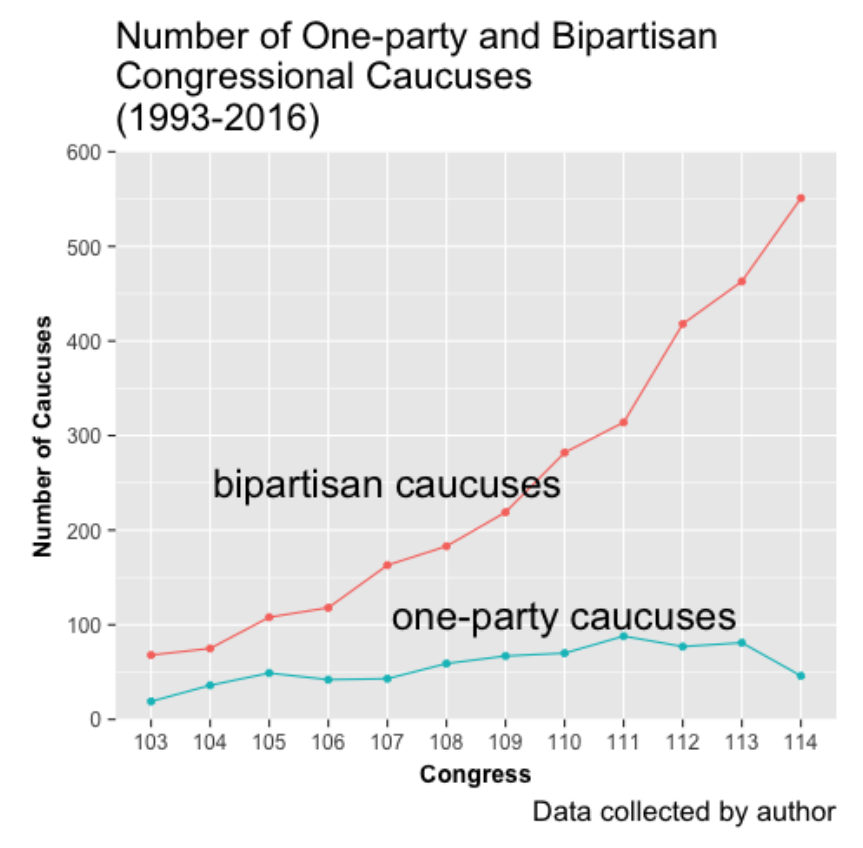

Figure 3 Number of one-party and bipartisan caucuses, 1993-2016

In addition, Error! Reference source not found. shows that the growth in the caucus population has primarily been among bipartisan caucuses.

For each Congress, I construct a matrix $(C)$ of legislators ( $i$ ) who self-identify their membership in caucuses (j), where $C$ contains a total of $N$ legislators and $M$ caucuses. I calculate the number of shared caucus memberships for each $(i, j)$ dyad by projecting a one-mode network of memberships from the two-mode matrix:

$$
S=C X C^{T}
$$

The resulting matrix, $S$, is $N x N$ and non-directed (symmetrical). Then, I extract unique dyads from $S$, eliminating self-loops and repeated dyads. The degree distribution of shared caucus memberships for each Congress generally follows a power-law distribution, as one would expect in relational data.

I calculate an eigenvector centrality score for each member in each congress, reflecting their centrality and connectedness in the network. Eigenvector centrality captures the extent to which each node is connected to other nodes that are of high or low degree, giving high scores to those with more relative connections. The eigenvector centrality of legislator $i$ is calculated as:

$$
x_{i}=\frac{1}{\lambda} \sum_{j \in M(i)} x_{j}
$$

where $j \in m(i)$ is the sum over all $j$ such that nodes $i, j$ are connected. Each legislator's eigenvector centrality score in the caucus network for each congress is expected to predict legislative effectiveness. 
In addition to the main independent variable of interest, I include a number of control variables in the models to help account for confounders.2

DWNOMINATE - I control for the linear ideological position of each legislator as measured by Poole/Rosenthal NOMINATE scores, which are based on roll call votes (Poole and Rosenthal 2011).

Party - A factor variable indicates whether each legislator is a Democrat, Republican, or Independent. Independent is the reference category.

Total terms served - A count of the total number of terms the legislator served in Congress at time $t$.

Leader - A dichotomous indicator variable that equals 1 when the legislator serves as a party leader, specifically the House Speaker, Majority Leader, Minority Leader, Majority Whip, and Minority Whip, or committee chairs.

Race - A factor variable that categorizes the race of the legislator as white, African American, Latino, Asian, or American Indian. White is the reference category.

Vote percent - An integer that describes the percentage of the popular vote the legislator earned in their previous election.

Power committee - A dichotomous indicator for legislators who serve on A-list House committees includes, Rules, Ways \& Means, or Appropriations.

It is important to note that I do not aim to test a causal relationship between caucus participation or committee participation and legislative effectiveness. Caucuses are used here as a proxy for voluntary connectivity among legislators. The measure is a reasonable proxy for the theoretical concepts of connectivity, and sufficiently allow me to test the hypotheses; however, because they are imperfect measures of the concepts, the findings show associations between the variables, not causal mechanisms.

In addition, there is still the possibility of selection bias. It is possible that a latent variable explains legislators' tendencies to join voluntary groups and their effectiveness as a legislator. Prior research on the relationship between connectivity and legislative effectiveness more adequately addresses this endogeneity problem than the current research (Battaglini, Sciabolazza, and Patacchini 2020). The present research has some advantages that this prior work does not because the model here includes 12

2 Notably, I do not include a control variable for ideological distance for two reasons. First, it is not clear that controlling for ideology adds sufficient explanatory value beyond political party, which is naturally controlled because the data only includes opposite-party dyads. Second, the dependent variable is co-voting change, which is based on rolls calls. Using a control variable, like NOMINATE, that is also based on roll calls would be difficult to interpret and add ambiguous heterogeneity to the model. 
congresses of data rather than 5 and uses co-caucus participation to measure connectivity rather than cosponsorship. Arguably, caucus participation is a more sensitive indicator of connectivity among legislators than cosponsorship, although both measures may be interpreted as cheap talk signalling.

While the research presented here cannot completely eliminate the possibility of selection bias, there is considerable qualitative evidence in the extant literature that is consistent with the theoretical model developed here. Scholars who have interviewed staff, legislators, and interest groups about their experience with caucuses find caucuses are an important source of novel relationships and information, and that they play a critical role in the policy making process (Hammond 2001; Ringe and Victor 2013). While I cannot rule out a selection effect of this type there is considerable extant evidence that selection effects alone do not fully explain observed changes in legislative behavior.

\section{Results}

I estimate a mixed linear-effects model using restricted maximum likelihood with fixed effects for time (congress), and random effects for legislators (repeated units). The model includes 4, 713 observations and demonstrates reasonable model fit. The complete results are in Table 1.

\begin{tabular}{lc}
\hline \multicolumn{2}{c}{ Legislative Effectiveness, 1993 - 2016 } \\
\hline Eigenvector Centrality Caucus Network & Legislative Effectiveness (SE) \\
DW NOMINATE(1) & $3.2983^{*}(1.3140)$ \\
Democrat & $-0.5060^{* *}(0.1641)$ \\
Republican & $1.2387(0.7223)$ \\
Terms served & $1.7148^{*}(0.7402)$ \\
Female & $0.0843^{* * *}(0.0064)$ \\
Leader & $0.0145(0.0762)$ \\
African American & $1.0735^{* * *}(0.0727)$ \\
Latino & $-0.2180^{*}(0.1054)$ \\
Asian & $-0.0127(0.1276)$ \\
American Indian & $-0.0683(0.2321)$ \\
Majority & $0.2107(0.7466)$ \\
Vote Percent & $1.1626^{* * *}(0.0399)$ \\
Power Committee & $-0.0003(0.0017)$ \\
Constant & $-0.3766^{* * *}(0.0554)$ \\
Congress dummies? & $-1.7256^{*}(0.7331)$ \\
$\mathrm{N}$ & Yes \\
Log Likelihood & 4,713 \\
AIC & $-7,755.8940$ \\
BIC & $15,565.7900$ \\
\hline P & $15,740.1600$ \\
\hline
\end{tabular}

${ }^{*} \mathrm{p}<.05 ;{ }^{* *} \mathrm{p}<.01 ;{ }^{* * *} \mathrm{p}<.001$

Linear mixed-effects model on individual legislative effectiveness using restricted maximum likelihood, estimated using R 'Ime4' package with fixed effects for congress and random effects for individuals. Standard errors shown in parentheses.

Table 1 Linear mixed-effects model on legislative effectiveness 
The results are more easily interpreted in the following graph.

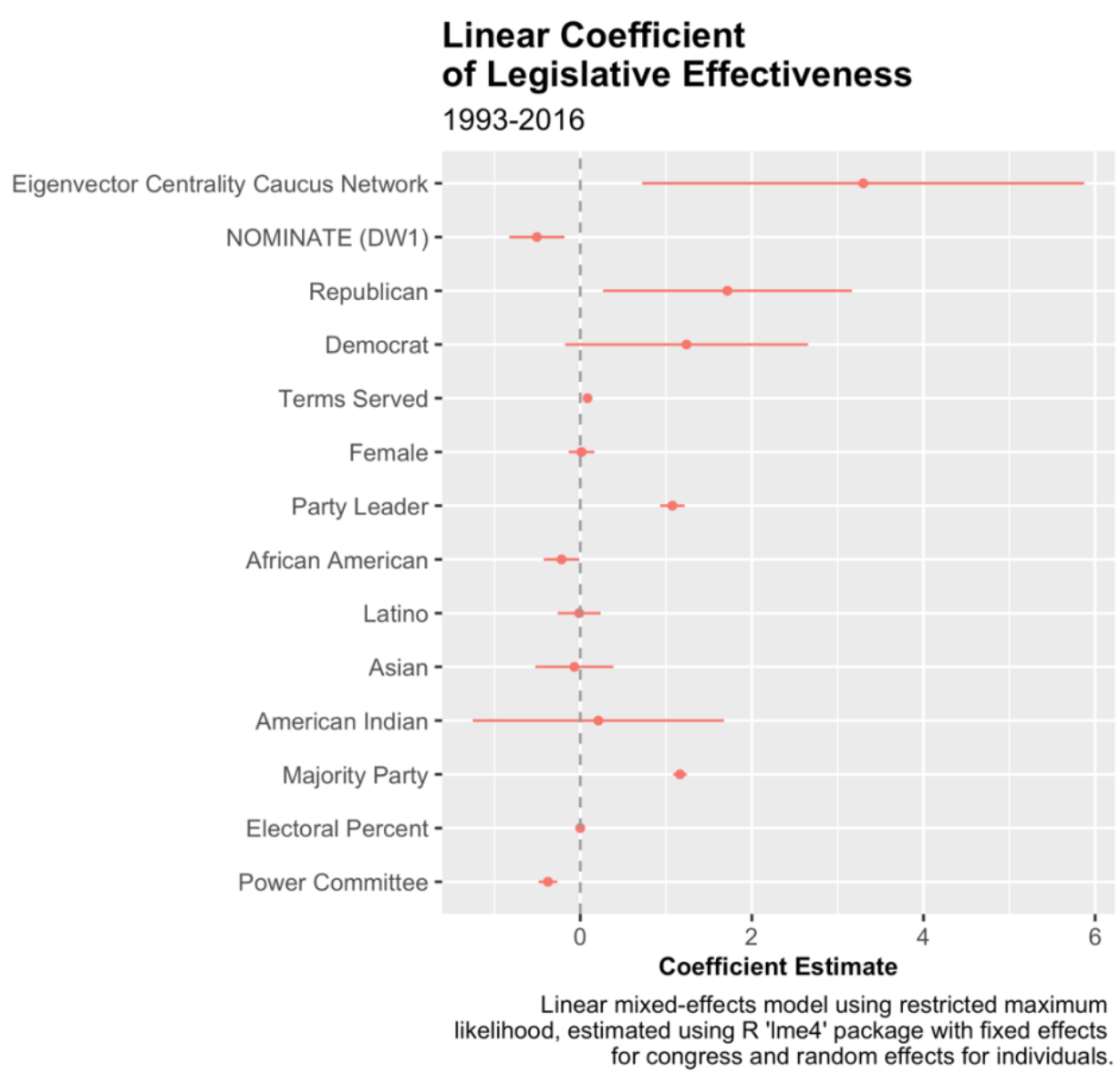

Figure 4 Coefficient estimates visualized from Table 1

The results are consistent with the expectation expressed in hypothesis 1: the more connected a legislator is in the caucus network, the higher their legislative effectiveness, all else being equal.

The model shows results that are similar to other findings related to legislative effectiveness, emphasizing some reliability behind the model. As in other research in this area, race and gender are largely independent of effectiveness, while institutional advantages such as being a party leader or in the majority party are strong predictors of effectiveness. Eigenvector centrality has a large standard error associated with the estimate, but even so, is distinguishable from zero. Institutions and connectivity are important factors for understanding legislative effectiveness. 


\section{Conclusion}

Institutions and relationships are important determinants of human behavior and therefore political outcomes. This paper develops a simple model that provides a framework for understanding the interdependence of institutions and relationships for understanding politics. The framework supposes that institutions are largely responsible for determining the actors that participate in a process, and the connections between those actors largely determine the constraints that govern their interactions. So institutions determine who plays, and the relationships among players determine further institutions. This endogenous process is tricky to measure and observe empirically, but an appreciation for the complexity of these interactions may help scholars unpack a variety questions related to political behavior and outcomes.

One observable implication of the theoretical framework described here is in the behavior of members of the US House of Representatives. I expect that legislators more connection to one another will be more legislatively effective in Congress. Using data from 12 congresses of data on legislative actors, institutions, and interactions, I show that legislators who are more connected via legislative caucuses are more effective legislators, holding constant a variety of other factors that are also associated with legislative effectiveness. The findings show that legislative effectiveness is a function of institutional features of congress (e.g., parties and committees) and relational connections between legislators, which is consistent with the broad theory articulated here. 


\section{Bibliography}

Battaglini, Marco, Valerio Leone Sciabolazza, and Eleonora Patacchini. 2020. "Effectiveness of Connected Legislators." American Journal of Political Science n/a (n/a). https://doi.org/10.1111/ajps.12518.

Berelson, Bernard R. 1954. Voting: A Study of Opinion Formation in a Presidential Campaign. University of Chicago Press.

Directories, Leadership. 2012. Congressional Yellow Book Winter 2012 Who's Who in Congress, Including Committees and Key Staff. Leadership Directories.

Downs, Anthony. 1957. An Economic Theory of Democracy. 1st edition. New York: Harper and Row.

Hammond, Susan Webb. 2001. Congressional Caucuses in National Policymaking. JHU Press.

Huckfeldt, Robert, and John Sprague. 1987. "Networks in Context: The Social Flow of Political Information." The American Political Science Review 81 (4): 11971216. https://doi.org/10.2307/1962585.

- - . 1988. "Choice, Social Structure, and Political Information: The Information Coercion of Minorities." American Journal of Political Science 32 (2): 467-82. https://doi.org/10.2307/2111132.

Lazarsfeld, Paul Felix, Bernard Berelson, and Hazel Gaudet. 1948. The People's Choice: How the Voter Makes Up His Mind in a Presidential Campaign. Columbia University Press.

McClurg, Scott D. 2006. "The Electoral Relevance of Political Talk: Examining Disagreement and Expertise Effects in Social Networks on Political Participation." American Journal of Political Science 50 (3): 737-54. https://doi.org/10.1111/j.1540-5907.2006.00213.x.

Mutz, Diana C. 2002. "Cross-Cutting Social Networks: Testing Democratic Theory in Practice." American Political Science Review 96 (1): 111-26. https://doi.org/10.1017/S0003055402004264.

Poole, Keith T., and Howard L. Rosenthal. 2011. Ideology and Congress. Transaction Publishers.

Riker, William. 1988. Liberalism Against Populism: A Confrontation Between the Theory of Democracy and the Theory of Social Choice. Prospect Heights, III: Waveland Pr Inc.

Riker, William H. 1980. "Implications from the Disequilibrium of Majority Rule for the Study of Institutions." The American Political Science Review 74 (2): 432. https://doi.org/10.2307/1960638.

Riker, William H., and Peter C. Ordeshook. 1968. "A Theory of the Calculus of Voting." The American Political Science Review 62 (1): 25-42.

Ringe, Nils, and Jennifer Nicoll Victor. 2013. Bridging the Information Gap: Legislative Member Organizations as Social Networks in the United States and the European Union. Ann Arbor, MI: University of Michigan Press.

Shepsle, Kenneth A. 1979. "Institutional Arrangements and Equilibrium in Multidimensional Voting Models." American Journal of Political Science 23 (1): 27-59. https://doi.org/10.2307/2110770. 
- - . 2010. Analyzing Politics: Rationality, Behavior and Instititutions, 2nd Edition. Second Edition edition. New York: W. W. Norton \& Company.

Sokhey, Anand E., and Paul A. Djupe. 2011. "Interpersonal Networks and Democratic Politics." PS: Political Science \& Politics 44 (1): 55-59. https://doi.org/10.1017/S1049096510001861.

Uslaner, Eric M. 1993. The Decline of Comity in Congress. 1 edition. Ann Arbor: University of Michigan Press.

Victor, Jennifer Nicoll, and Nils Ringe. 2009. "The Social Utility of Informal Institutions Caucuses as Networks in the 110th U.S. House of Representatives." American Politics Research 37 (5): 742-66. https://doi.org/10.1177/1532673X09337183.

Volden, Craig, and Alan E. Wiseman. 2014. Legislative Effectiveness in the United States Congress: The Lawmakers. New York, NY: Cambridge University Press.

Wasserman, Stanley, and Katherine Faust. 1994. Social Network Analysis: Methods and Applications. 1 edition. Cambridge ; New York: Cambridge University Press. 